\title{
Central Neuraxial Blockade-Assisted External Cephalic Version in Reducing Caesarean Section Rate: Systematic Review and Meta-Analysis
}

\author{
Ibrahim Bolaji ${ }^{1}$ and Lillian Alabi-Isama ${ }^{1,2}$ \\ ${ }^{1}$ Family Services Division, Department of Obstetrics and Gynaecology, Hull York Medical School (HYMS), \\ Diana Princess of Wales Hospital, Northern Lincolnshire and Goole Hospitals NHS Foundation Trust, \\ Scartho Road, Grimsby DN33 2BA, UK \\ ${ }^{2}$ Clinical Research Fellow, Division of Surgery, Oncology, Reproductive Biology and Anaesthetics, Imperial College, \\ Hammersmith Campus, Du cane Road, London W120NN, UK \\ Correspondence should be addressed to Ibrahim Bolaji, iibolaji@yahoo.com
}

Received 14 September 2009; Accepted 18 November 2009

Recommended by Anthony O. Odibo

\begin{abstract}
We review the medical literature on the success, safety and economic value of central neuraxial blockade-assisted (CNB) external cephalic version from randomized controlled studies identified from 1951 to 2009. The result showed that more women had successful ECV with regional anaesthesia with corresponding reduction in caesarean section rate. They were 1.5 times more likely than women not receiving anaesthesia to have a successful ECV. The number to treat is six women needed to receive anaesthesia for 1 baby to be turned from breech to cephalic presentation. Feto-maternal morbidity was not increased in the CNB-aided group consisting of only transient bradycardia. Although the appropriate amount of force for safe version has not been quantified, there was no report of uterine rupture despite removal of these patients from "excessive force-pain biofeedback loop" induced through motor nerve blockade. We can attribute $30 \%$ of cost savings amounting to $£ 42,150.00$ directly to CNB using the most up to date Health Resource Group Code (HRG4). The initial results are encouraging but until the benefits and safety of CNB-aided ECV are substantiated by large randomized, blinded controlled trials, this practice cannot be universally recommended.
\end{abstract}

Copyright ( $) 2009$ I. Bolaji and L. Alabi-Isama. This is an open access article distributed under the Creative Commons Attribution License, which permits unrestricted use, distribution, and reproduction in any medium, provided the original work is properly cited.

\section{Introduction}

The problem of rising caesarean section is one of paramount importance and continues to be of increasing interest and concern. This increase is not limited to Europe [1] but global [2] and although this increase involves principally the lower segment procedure, classical caesarean section has not been excluded [3]. Despite the growing national and international trend some units still maintain a relatively low caesarean section rate (CSR) (Table 1$)$.

One suggested reason for the rise is increasing requests by women for caesarean section (CS) in the absence of clear medical indications such as placenta praevia and arguably, breech presentation, or previous caesarean section $[4,5]$.

Several authors have suggested a number of strategies for reducing CSR $[1,6-8]$, particularly "primary C-section," including external cephalic version (ECV). Turning the fetus to the cephalic/vertex position by external manipulation has been identified as the only clinical intervention with demonstrated grade A evidence of reducing CS overall [6].

Approximately $4 \%$ of term singleton babies present as a breech [9]. This accounts for nearly $20 \%$ of primary CS and this rate is rising [1]. This increase is partly due to "defensive obstetrics" and has been more dramatic following the publication of the term breech trial [10]. Consequently, a trial of ECV at term has become increasingly popular. The majority of women would prefer a vaginal birth (VB) [11] although most would choose CS if there is a medical indication [12]. For single fetus in breech presentation, CS has been shown to be safer for the fetus than VB $[10,13]$ and the majority now recommend CS for term breech presentation [14]. Although the risks associated with 
TABLe 1: Eight-year review of caesarean sections-Diana, Princess of Wales Hospital, Grimsby $\mathrm{UK}^{\perp}$.

\begin{tabular}{|c|c|c|c|c|c|c|c|c|}
\hline \multirow{2}{*}{ Year } & \multirow{2}{*}{ Deliveries } & \multirow{2}{*}{ Babies } & \multicolumn{2}{|c|}{ Caesarean section } & \multicolumn{2}{|c|}{ Emergency C-section $^{\perp}$} & \multicolumn{2}{|c|}{ Elective C-section $^{\perp \perp}$} \\
\hline & & & $\mathrm{N}$ & $\%$ & $\mathrm{~N}$ & $\%$ & $\mathrm{~N}$ & $\%$ \\
\hline \multicolumn{9}{|c|}{ 5-Year review* } \\
\hline 2001 & 1951 & 1979 & 362 & $18.60 \%$ & 203 & $11 \%$ & 159 & $8 \%$ \\
\hline 2002 & 1973 & 1992 & 344 & $17.40 \%$ & 194 & $10 \%$ & 150 & $8 \%$ \\
\hline 2003 & 2069 & 2106 & 387 & $18.70 \%$ & 221 & $11 \%$ & 166 & $8 \%$ \\
\hline 2004 & 2235 & 2261 & 405 & $18.10 \%$ & 238 & $11 \%$ & 167 & $8 \%$ \\
\hline 2005 & 2350 & 2384 & 387 & $16.40 \%$ & 258 & $11 \%$ & 129 & $6 \%$ \\
\hline Total & 10578 & 10722 & 1885 & $17.84 \%$ & 1114 & $10.80 \%$ & 771 & $7.60 \%$ \\
\hline \multicolumn{9}{|c|}{8 -Year review ${ }^{* *}$} \\
\hline 2006 & 2420 & 2458 & 413 & $17.10 \%$ & 233 & $10 \%$ & 180 & $8 \%$ \\
\hline 2007 & 2458 & 2535 & 450 & $18.10 \%$ & 240 & $10 \%$ & 210 & $8 \%$ \\
\hline 2008 & 2508 & 2577 & 415 & $16.30 \%$ & 213 & $8 \%$ & 202 & $3 \%$ \\
\hline Total & 17964 & 18292 & 3163 & $17.59 \%$ & 1800 & $10.25 \%$ & 1363 & $7.13 \%$ \\
\hline
\end{tabular}

${ }^{\perp}$ Diana, Princess of Wales Hospital, Grimsby serves a fairly stable predominantly working class population of about 91000 in the Northeast Lincolnshire, UK. ${ }^{\perp \perp}$ C-Section-Lower segment caesarean section. *Five-year review was from January 1, 2001 to December 31, 2005. ** Eight-year review was from January 1 , 2001 to December 31, 2008.

operative delivery are low, it is not without fetomaternal incidents and CS remains the largest contributing factor to the incidence of maternal morbidity and mortality in the pueperium [15]. Operative delivery quadruples the risk of severe morbidity compared to VB [16-18].

The rationale for ECV is to reduce the incidence of breech presentation at term, the associated risks of vaginal breech delivery, and also the risk of avoidable caesarean section [7]. Success rates for ECV have been variable, ranging from $35 \%-$ $86 \%$ with an average of $58 \%$, and a number of strategies have been proposed to improve this, thereby reducing the CSR.

Tocolytics have been used in this regard in the last three decades [19], with initial studies reporting success rates of about $60 \%-80 \%[19,20]$. Terbutaline was found to be the most commonly used beta-sympathomimetic agent to achieve tocolysis prior to ECV.

A recent Cochrane Database of systemic reviews on interventions to help ECV concluded that routine tocolysis appears to reduce the failure rate of ECV at term [21]. Although the reduction of noncephalic presentations at birth was not statistically significant, there was, however, a reduction in the number of CSs [21].

Nonmedical interventions to improve spontaneous version rate have been described by several authors. They include postural techniques, entailing relaxation with the pelvis in an elevated position (knee-chest position assumed with full bladder) [22], "Indian Version" [23], Vibroacoustic stimulation for midline spine position [24], transabdominal amnioinfusion with warmed saline [25], acupuncture [26], and complementary medicine in form of moxibustion. The latter is a traditional Chinese medicine involving the burning of a herb, Artemisia vulgaris, close to the skin to induce warming sensation [27]. There is, however, insufficient evidence to support these methods. Other alternatives including the use of hypnosis and acupuncture or moxibustion to the acupuncture point bladder 67 (BL67), located at the tip of the fifth toe [26], have been poorly researched. A recent randomized controlled trial on moxibustion for breech version [27] showed no beneficial effect. Despite this lack of proven effectiveness, women had positive opinions of the intervention.

\section{Method}

This paper reviews the medical literature to determine the success, safety, and economic value of regional anaesthesiaassisted ECVs.

The inclusion criteria include clinical trials evaluating ECV success using both randomized and nonrandomized trials. The interventions studied were all methods of maternal anaesthesia including general anaesthetic, central neuraxial anaesthesia (CNB), or analgesia used to aid ECV.

The primary outcome was the proportion of participants with a successful external cephalic version at the end of the attempts. Secondary outcomes included fetal presentation at delivery, method of delivery, fetal morbidity and mortality, and maternal morbidity.

Articles were identified in searches using the following electronic databases: MEDLINE (MEDLARS OnLine), Cochrane, and RCOG using DIALOG Information Retrieval Service covering the period 1960-2009 under the following medical subject heading key words: external cephalic version and anaesthesia or analgesia in either the heading or text words.

Hand searches of the articles identified within references were conducted as well as searches from the International Journal of Obstetric Anaesthesia and the published abstracts of the annual meetings of the American Society of Anaesthesiologists and the Canadian Anaesthesia Society. All attempts were made to identify relevant data on this topic.

Two reviewers (L. AI and I. IB) inspected titles and abstracts of all the references retrieved from the search to select all potentially relevant studies. Studies that met the inclusion criteria were categorized. Each potentially relevant 
study was then reviewed to identify randomized control trials.

Results from the randomized trials were combined using random effects model. The primary outcome which is successful ECV was expressed in relative risk (RR) with $95 \%$ confidence intervals. An RR of greater than 1.0 would indicate the proportion of women with successful ECV with anaesthesia over those without anaesthesia. Statistical significance was defined as a $P$ value $<.05$ and if the $95 \%$ confidence interval (CI) did not include 1.0. Numbers needed to treat (NNT) are the inverse of the Absolute Risk Reduction $(\mathrm{NNT}=1 / \mathrm{ARR})$ and absolute risk reduction (ARR) is the experimental event rate-control event rate.

Twenty nine studies were identified from initial literature search and reviewed. The articles ranged in publication from 1951 to 2009. Of these, 22 were nonrandomized prospective and retrospective studies. Only seven articles were randomized controlled trials including two studies comparing the use of epidural anaesthesia $[28,29]$ with no anaesthesia, four studies compared the use of spinal anaesthesia [30-33] with no anaesthesia, and one study compared the use of combined spinal and epidural anaesthesia [34] with no anaesthesia. Six of the 7 studies were conducted in the US, the seventh study was conducted in Israel, and all seven studies were published between 1997 and 2009. The study by Delisle et al. [32] was published in abstract form with limited study information available. There were 681 women participating in the seven studies with 339 women receiving either epidural or spinal anaesthesia, 47 women receiving intravenous fentanyl, and 295 receiving no anaesthetic.

\section{Effectiveness of Central Neuraxial Blockade-Assisted External Cephalic Version}

There has been renewed interest in the practice of central neuraxial blockade-assisted ECV at term especially in the USA. Central neuraxial blocks are a group of anaesthetic techniques which include epidurals, spinals, and combined spinal epidurals (CSEs). All are invasive techniques involving injection of pain relieving drugs into the vertebral canal (spinal) and epidural space (epidural) and requiring a needle to be placed close to the central nervous system. CNB has the potential to provide patients with optimal pain relief but can also lead to patient harm. The 3rd National Audit Project of the Royal College of Anaesthetists [35] provides reassuring results for the use of this technique.

It is known that ECV does not currently play a significant role in the management of breech presentation and that epidural-assisted ECV might improve success rates. Preterm $\mathrm{ECV}$ is a subject of an ongoing international multicentre randomized study [36] and is not considered in this review.

ECV is at the very least uncomfortable, if not overtly painful and is associated with maternal anxiety. Maternal discomfort and anxiety are associated with higher rates of failure of ECV and for that reason regional anaesthesia has been proposed to facilitate ECV. The rationale for the inclusion is that whilst tocolytic agent provides uterine relaxation, $\mathrm{CNB}$ provides abdominal muscular relaxation through motor nerve block hence its effects on maternal pain, muscle tone, and anxiety. General anaesthesia has been used in the past for ECV but was abandoned following reports of fetal mortality, which in some series reached $1 \%$ [37].

A retrospective study in the setting of previously failed ECV attempts by Cherayil et al. [31] showed that the success rates in nulliparous women reattempted with spinal and epidural anaesthesia were $4 / 5(80 \%)$ and 5/6 (83\%), respectively. Success rates in multiparous women reattempted with spinal and epidural anaesthesia were $1 / 1(100 \%)$ and $3 / 3$ $(100 \%)(P=\mathrm{NS})$. High ECV success rates were noted in nulliparous $(9 / 11[82 \%])$ and multiparous $(4 / 4$ [100\%] $(P=.36)$ women, respectively. Overall, $8 / 9(89 \%)$ and 5/6 $(83 \%)(P=\mathrm{NS}) \mathrm{ECV}$ attempts were successful with epidural and spinal anaesthesia, respectively.

In a retrospective cohort study by Carlan et al. [38], ECV at term was successful in 59\% of 32 women with epidural analgesia, and $24 \%$ of 37 women without anaesthesia. Albeit a retrospective analysis and limited as well by a relatively small number of patients, the study shows an encouraging increase in the success rate for ECV performed with epidural analgesia. This is an impressive difference, because in the epidural group there were relatively more versions performed by nonconsultant grade and more patients with advanced cervical dilatation or even in labour. Both of these factors would be expected to decrease success in the study group. In addition, of the 28 patients who failed a first attempt at version without anaesthesia, 7 patients had successful versions when a second attempt was performed with CNB.

In an uncontrolled study, ECV under epidural analgesia was successful in nine (56\%) of 16 women in whom initial attempts had failed $[39,40]$

Several randomized controlled trials have compared the use of regional anaesthesia with no anaesthesia before performing ECV. Weiniger et al. [30], in a randomized control trial of ECV using regional anaesthesia amongst nulliparous women showed that ECV was more successful in the women who were randomized to receive spinal anaesthesia (24 of 36 [66.7\%] compared with 11 of 34 [32.4\%], who did not receive spinal anaesthesia $(P=.04)$. Fifteen women in the control group had unsuccessful version due to pain that did not allow a sufficient ECV attempt and all fifteen were offered subsequent spinal anaesthesia. Eleven of them had successful ECV under spinal anaesthesia. Sullivan et al. [34] randomized 48 women to receive combined spinal and epidural anaesthesia (CSE) and 47 women to receive intravenous fentanyl (SYS) and showed that a success rate of ECV was $47 \%$ with CSE and $31 \%$ in the SYS group $(P=.14)$. There was no difference in the rate of successful ECV or vaginal delivery with CSE compared to intravenous fentanyl analgesia. Pain scores were lower and satisfaction higher with CSE analgesia, and median time to fetal heart rate reactivity was shorter in the CSE group.

A meta-analysis by Marcarthur et al. [41] compared four prospective randomized studies measuring the success rate of ECV performed using neuraxial analgesia and described an overall success rate of $50 \%$. They found that more women 
TABLE 2: Success rates of central neuraxial block-aided ECV-discordant randomized trials.

\begin{tabular}{|c|c|c|c|c|}
\hline Study & ${ }^{*}$ Gestational age & Treatment (\%) & Control (\%) & RR (95\% CI) \\
\hline \multicolumn{5}{|l|}{ EPIDURAL } \\
\hline Schorr et al. [29] & $>37$ weeks & $24 / 35(68.6)$ & $11 / 34(32.4)$ & $2.12(1.24,3.62)$ \\
\hline Mancuso et al. [28] & $>37$ weeks & $32 / 54(59.3)$ & $18 / 54(33.3)$ & $1.78(1.15,2.75)$ \\
\hline Total & & 89 & 88 & $1.90(1.38,2.64)$ \\
\hline \multicolumn{5}{|l|}{ SPINAL } \\
\hline Weiniger et al. [30] & $>37$ weeks & $24 / 36(66.7)$ & $11 / 34(32.4)$ & $2.06(1.25,3.43)$ \\
\hline Dugoff et al. [31] & 38 weeks & $22 / 50(44.0)$ & $22 / 52(42.3)$ & $1.04(0.67,1.62)$ \\
\hline Delisle et al. [32] & Unknown & $41 / 99(41.4)$ & $31 / 102(30.4)$ & $1.36(0.94,1.98)$ \\
\hline Hollard [33] & $>37$ weeks & $9 / 17(52.9)$ & $10 / 19(52.6)$ & $1.01(0.54,1.82)$ \\
\hline Total & & 202 & 207 & $1.31(1.04,1.66)$ \\
\hline \multicolumn{5}{|l|}{${ }^{\perp} C S E$} \\
\hline Sullivan [34] & $>36$ weeks & $22 / 48(45.8)$ & 18/47 (38.3) & $1.19(0.74,1.92)$ \\
\hline Overall Total & & 339 & 342 & $1.45(1.21,1.72)$ \\
\hline
\end{tabular}

${ }^{*}$ Gestational age when ECV was performed. ${ }^{\perp} \mathrm{CSE}$ combined spinal and epidural.

had successful ECV if they received regional anaesthesia $(119 / 238 ; 50 \%)$ compared to women who did not receive anaesthesia $(82 / 242 ; 34 \%)$.

There was discordance between the trials included in our review (Table 2). ECV failure was significantly reduced in the two trials using epidural anaesthesia $[28,29]$ but no difference was found in the trial by Dugoff et al. [31]. Schorr et al. [29] demonstrated a significant beneficial effect of anaesthesia in both primary and secondary outcomes. Only one women in the control group reverted from a cephalic version to a breech after successful ECV compared to none in the anaesthetic group. The number of caesarean sections in the control group was more than those in the treatment group. In the study by Macusso et al. [28], there was no statistical difference between the groups in gestation at the time of procedure, placental location, fetal lie, estimated fetal weight, or amniotic fluid index but ECV was successful in 32 of 54 women $(59 \%)$ with epidural anaesthesia compared with 18 of $54(33 \%)$ with no anaesthesia (RR 1.78, 95\% CI $1.15,2.75, P<.05)$. Vaginal delivery occurred in 29 of 54 women $(54 \%)$ in the treatment group and 16 of 54 women (30\%) in the control group (RR 1.81, 95\% CI 1.14, $2.92, P<.05)$. The study by Weiniger et al. [30] showed that successful ECV occurred among 24/36 (66.7\%) women randomized to receive spinal analgesia compared with 11 of $34(32.4 \%)$ without anaesthesia (RR 2.06, 95\% CI of 1.25 , $3.43 ; P<.05)$. This contradicted the spinal study by Dugoff et al. [31] where there was no statistical difference between the anaesthetic $\{22 / 50(44.0 \%) P=.03\}$ and no anaesthetic group $\{(22 / 52(42.3 \%) P=.1\}$.

\section{Safety of Central Neuraxial Blockade-Assisted External Cephalic Version}

One major concern has traditionally been that if the patient is removed from "excessive force-pain biofeedback loop," then there is potential risk that ECV facilitated by regional block could lead to use of excessive force. This may result in increased incidence of abruption, Rh-isoimmunisation, uterine rupture, cord prolapse, and other serious conditions. Fetal morbidity was not increased in the group that had regional anaesthesia consisting only of a transient bradycardia $(9.9 \% ; 26 / 263)$. One attempt in both spinal and epidural group was associated with fetal bradycardia needing caesarean section with APGAR scores of 8 and 9 at 1 and 5 minutes, respectively [42]. The outcome of fetal morbidity was not calculated as there was no fetal or neonatal death. Although the appropriate amount of force for safe version has not been quantified, there have been no reports of uterine rupture during attempted ECV under neuraxial analgesia (Table 3).

In our unit, we adopt "the rule of 3 " which consists of three criteria for stopping the ECV (Table 4). The procedure is discontinued if the woman reports undue discomfort, if the fetal heart tones are nonreassuring or there is unsuccessful version after three manoeuvres.

Stephen Pratt $[44,45]$ has argued in favour of epidural use for ECV. He suggested that the use of continuous fetal monitoring and real time ultrasound scan is now routine during ECV, allowing the clinician to closely monitor mother and baby, thereby greatly decreasing the risk of catastrophic events.

On the other hand, there is the risk of epidural anaesthesia [35] such as dural puncture and headaches, haematoma, and other neurological complications. One plausible way of reducing the risk of regional anaesthesia is to delay this procedure until the onset of established labour when epidural can be offered for pain relief but the downside is the membranes may have ruptured already hence, reducing the success of the ECV attempt. Neuraxial anaesthesia can be used selectively in women with failed attempts or very anxious women in an environment where Caesarean delivery is immediately possible if the version fails or significant complication occurs monitored by cardiotocograph. 
TAble 3: Summary of Central Neuraxial Blockade-Assisted ECV Trials.

\begin{tabular}{|c|c|c|c|c|}
\hline Author/Year & Type of Study & Subjects & Success of ECV & Complications \\
\hline Carlan et al. [38] (1994) & $\begin{array}{l}\text { Retrospective chart } \\
\text { review at }>36 \\
\text { weeks }\end{array}$ & $\begin{array}{l}32 \text { epidural; } 37 \\
\text { control }\end{array}$ & $\begin{array}{l}59 \% \text { success and } 54 \% \\
\text { vag del; } 24 \% \text { and } 21 \% \\
\text { in control }\end{array}$ & $\begin{array}{l}7 \text { bradycardia, } 1 \\
\text { abruption with } \\
\text { epidural; } 2 \text { and } 1 \text { in } \\
\text { control }\end{array}$ \\
\hline Schorr et al. [29] (1997) & $\begin{array}{l}\text { Prospective } \\
\text { randomized at }>37 \\
\text { weeks }\end{array}$ & $\begin{array}{l}35 \text { epidural; } 34 \\
\text { control }\end{array}$ & $\begin{array}{l}69 \% \text { success; } 66 \% \\
\text { vaginal delivery in } \\
\text { epidural group; } 32 \% \\
\text { and } 31 \% \text { in control }\end{array}$ & NA \\
\hline Dugoff et al. [31] (1999) & $\begin{array}{l}\text { Prospective } \\
\text { randomized }\end{array}$ & $\begin{array}{l}50 \text { spinal; } 52 \\
\text { control }\end{array}$ & $\begin{array}{l}44 \% \text { success in spinal } \\
\text { group; } 42 \% \text { control }\end{array}$ & $\begin{array}{l}11 \text { bradycardia, } 4 \\
\text { hypotension with } \\
\text { spinal; } 6 \text { bradycardia, } 1 \\
\text { abruption, } 4 \text { patient } \\
\text { pain in control }\end{array}$ \\
\hline Mancuso et al. [28] (2000) & $\begin{array}{l}\text { Prospective } \\
\text { randomized at }>37 \\
\text { weeks }\end{array}$ & $\begin{array}{l}54 \text { epidural; } 54 \\
\text { control }\end{array}$ & $\begin{array}{l}59 \% \text { success and } 54 \% \\
\text { vag del in epidural } \\
\text { group; } 33 \% \text { and } 30 \% \\
\text { in control }(P<.05)\end{array}$ & $\begin{array}{l}4 \% \text { bradycardia in } \\
\text { epidural group; } 6 \% \text { in } \\
\text { control }\end{array}$ \\
\hline Birnbach et al. [43] (2001) & $\begin{array}{l}\text { Prospective open at } \\
>36 \text { weeks }\end{array}$ & $\begin{array}{l}20 \text { received } \\
\text { spinal analgesia; } \\
15 \text { did not }\end{array}$ & $\begin{array}{l}80 \% \text { success in spinal } \\
\text { group; } 33 \% \text { in control }\end{array}$ & $\begin{array}{l}\text { Fetal bradycardia } \\
\text { requiring section in } \\
1 \text { pt. in control group }\end{array}$ \\
\hline Delisle et al. [32] (2001) & $\begin{array}{l}\text { Prospective } \\
\text { randomized }\end{array}$ & $\begin{array}{l}99 \text { spinal; } 102 \\
\text { control }\end{array}$ & $\begin{array}{l}41 \% \text { success in spinal } \\
\text { group; } 30 \% \text { control }\end{array}$ & Unknown \\
\hline Hollard et al. [33] (2003) & $\begin{array}{l}\text { Prospective } \\
\text { randomized }\end{array}$ & $\begin{array}{l}17 \text { spinal; } 19 \\
\text { control }\end{array}$ & $\begin{array}{l}52.9 \% \text { success in spinal } \\
\text { group; } 52.6 \% \text { control }\end{array}$ & $\begin{array}{l}1 \text { placenta abruption in } \\
\text { spinal group }\end{array}$ \\
\hline Weiniger et al. [30] (2007) & $\begin{array}{l}\text { Prospective } \\
\text { randomized at }>37 \\
\text { weeks }\end{array}$ & $\begin{array}{l}36 \text { spinal; } 34 \\
\text { control }\end{array}$ & $\begin{array}{l}66.7 \% \text { success in spinal } \\
\text { group; } 32.4 \% \text { control }\end{array}$ & $\begin{array}{l}2 \text { transient bradycardia, } \\
7 \text { hypotension }\end{array}$ \\
\hline Sullivan et al. [34] (2009) & $\begin{array}{l}\text { Prospective } \\
\text { randomized at } \geq 36 \\
\text { weeks }\end{array}$ & $\begin{array}{l}22 \mathrm{CSE}^{\perp} ; 18 \mathrm{IV} \\
\text { fentanyl }\end{array}$ & $\begin{array}{l}45.8 \% \text { success in CSE } \\
\text { group; } 38.3 \% \text { IV } \\
\text { fentanyl group }\end{array}$ & $\begin{array}{l}1 \text { bradycardia in each } \\
\text { group needing EMCS* }\end{array}$ \\
\hline
\end{tabular}

${ }^{\perp} \mathrm{CSE}$ combined spinal and epidural. * EMCS Emergency Caesarean Section.

TABLE 4: Grimsby ECV rule of three ${ }^{ \pm}$.

\begin{tabular}{lc}
\hline & Criteria for stopping external cephalic version (ECV) \\
\hline 1 & Undue Maternal Discomfort \\
2 & Non-reassuring Fetal Heart Tones/Patterns \\
3 & Unsuccessful version after three manoeuvres \\
\hline
\end{tabular}

${ }^{ \pm} \mathrm{ECV}$ is discontinued if one of the above 3 criteria occurs

\section{Cost Effectiveness of Central Neuraxial Blockade-Assisted External Cephalic Version}

We use the new Health Resource Groups [46] (HRG) for cost calculation. HRGs are standard groupings of clinically similar treatments which use common levels of healthcare resource. They enable the comparison of activity within and between different organisations with the National Health Service.

National tariff is the national price for each HRG for each patient spell in hospital. There are separate tariffs for elective and emergency care and providers are compensated for unavoidable regional cost differences. Their use as consistent "units of currency" supports standardised healthcare commissioning across the service. The previous version of HRGs (v3.5) has been used since 2003 but lately the Casemix service has introduced a major revision, HRG4 [47], which was commissioned by the Department of Health $(\mathrm{DoH})$, to support the policy of payment by results [48] (PbR) from 2009-10 for payment.

Using the most up to date HRG4 code, the cost of HRG NZO3A (national tariff for CS 19 years and over) minus HRG cost NZO1B (national tariff for normal delivery 19 years and over without complications) for each successful version would generate an estimated savings of $\mathfrak{£} 1,405.00$ (Table 5). The use of CNB adds approximately 30 successful versions per 100 attempts (i.e., from $25 \%-30 \%$ success rate up to $55 \%-60 \%$ ) [45]. We can attribute $30 \%$ of this cost saving or $\mathfrak{E} 42,150.00$ pounds sterling directly to the CNB. In the new HRG version 4 there is no individual cost for epidural as this is absorbed into the cost of the maternity event itself. If we adopt a conservative estimate of 15\% (as not all successful versions will deliver vaginally) or an additional 15 successful versions/100, the cost saving per regional block would be $£ 21,750.00$. This is similar to results of previous studies $[44,49]$.

If delivery is planned immediately after attempted ECV, the epidural could be used for labour analgesics if the version 
TABLE 5: Delivery Event National ${ }^{ \pm}$PbR Tariffs 2008-09 \& 2009-10 ${ }^{\perp}$

\begin{tabular}{|c|c|c|}
\hline \multicolumn{3}{|c|}{ 2008-09 } \\
\hline HRG V3.5 & Description & ${ }^{* *}$ Cost in $\mathfrak{E}$ \\
\hline N06 & Normal Delivery with $\mathrm{CC}^{ \pm}$ & 996 \\
\hline N07 & Normal Delivery without CC & 996 \\
\hline N08 & Assisted Delivery with CC & 2029 \\
\hline N09 & Assisted Delivery without CC & 1422 \\
\hline N10 & Caesarean Section with CC & 3077 \\
\hline N11 & Caesarean Section without CC & 2198 \\
\hline \multicolumn{3}{|c|}{$2009-10$} \\
\hline HRG V4 & Description & ${ }^{* *}$ Cost in $\mathfrak{E}$ \\
\hline NZ01A & Normal delivery 19 years and over with CC & 1881 \\
\hline NZ01B & Normal delivery 19 years and over without CC & 1174 \\
\hline NZ01C & Normal delivery 18 years and under with CC & 1921 \\
\hline NZ01D & Normal delivery 18 years and under without CC & 1177 \\
\hline NZ02A & Assisted delivery with CC & 2288 \\
\hline NZ02B & Assisted delivery without CC & 1728 \\
\hline NZ03A & Caesarean Section 19 years and over & 2579 \\
\hline NZ03B & Caesarean Section 18 years and under & 2654 \\
\hline NZ03C & Caesarean Section with complications & 3626 \\
\hline
\end{tabular}

${ }^{\perp}$ Adapted from HRG4 [41]. ${ }^{ \pm}$CC Complications. ${ }^{* *}$ Cost is expressed in pounds (E) Sterling. ${ }^{ \pm}$PbR Payment by Result.

is successful or for operative delivery if it fails. The later practice would limit any additional cost attributable to the version, particularly those related to nursing or hospital charges which would make the cost-benefit analysis even more favourable. There is currently no incentive such as financial benefits for units pursuing strategies to reduce Caesarean section as the hospitals get paid for services rendered under the $\mathrm{PbR}$.

It is anticipated that there would be a commitment by the DoH to make a proportion of providers' income conditional on quality and innovation, through the Commissioning for Quality and Innovation [50] (CQUIN) payment framework.

For the acute sector, this would be through a CQUIN scheme linking payment to specific locally determined goals. Our trust and Yorkshire and Humber NHS organisations are one of the front runners to sign up to delivery of a regional set of quality indicators as the mechanism for delivering the nationally set CQUIN policy. This option will be available in 2009/10 as an interim stage.

\section{Conclusion}

This systematic review compared seven randomized controlled trials and found more women had successful ECV if they received regional anaesthesia $(174 / 339 ; 51.3 \%)$ than women who did not receive anaesthesia (103/295; 34.9\%). Thus women receiving anaesthesia were 1.5 times more likely than women not receiving anaesthesia to have a successful ECV (95\% CI 1.22-1.77). Number needed to treat (NNT) is 6 women needed to receive anaesthesia for 1 baby to be turned from a breech to cephalic presentation.

It showed CNB-aided ECV as an additional tool for women with breech-presenting fetus. When successful, it may reduce CS in the index pregnancy and may allow for normal deliveries in subsequent pregnancies without the risk of trial of scar or placental accretism. A limitation of all the trials is that relatively few women have been involved in the randomized control trials comparing both groups; so estimates of maternal and fetal risks with CNB cannot be quantified. Furthermore, the obstetricians were not blinded to the presence or absence of anaesthesia in these trials. This is bound to influence the operators view to pursue a successful version as well as operators own bias. In the reports of Delisle et al. [32] and Hollard et al. [33], the method of random allocation was not specified.

There is no optimal gestational age for which this method could be applied. While delivery immediately following ECV would make the cost benefit analysis more favourable, there is concern that waiting until term to attempt ECV will potentially reduce the success rate and risk onset of spontaneous labour which also reduces success rate or may even be a relative contraindication to attempt ECV.

There was no information about the most important outcome which is avoidance of C-section. Not every successful version will deliver vaginally and some may revert while others may require intrapartum CS as high as $16.9 \%$ [51]. Because of conflicting results, the use of regional anaesthesia for facilitating external cephalic version cannot be recommended at this stage. A larger randomized, blinded (which would be difficult if not impossible) controlled trial is required to evaluate the safety and success of this practice.

\section{References}

[1] I. I. Bolaji and F. P. Meehan, "Caesarean section survey in Galway-1973 through 1987," European Journal of Obstetrics 
Gynecology and Reproductive Biology, vol. 48, no. 1, pp. 1-8, 1993.

[2] I. I. Bolaji and F. P. Meehan, "Post caesarean section delivery," European Journal of Obstetrics Gynecology and Reproductive Biology, vol. 51, no. 3, pp. 181-192, 1993.

[3] I. I. Bolaji, N. M. Rafla, and M. J. Mylotte, "Classical caesarean section through the posterior uterine wall," Irish Journal of Medical Science, vol. 161, no. 2, pp. 46-47, 1992.

[4] S. Paterson-Brown, "Should doctors perform an elective caesarean section on request? Yes, as long as the woman is fully informed," British Medical Journal, vol. 317, no. 7156, pp. 462$463,1998$.

[5] O. Amu, S. Rajendran, and I. I. Bolaji, "Should doctors perform an elective caesarean section on request? Maternal choice alone should not determine method of delivery," British Medical Journal, vol. 317, no. 7156, pp. 463-465, 1998.

[6] R. Walker, D. Turnbull, and C. Wilkinson, "Strategies to address global cesarean section rates: a review of the evidence," Birth, vol. 29, no. 1, pp. 28-39, 2002.

[7] RCOG guideline No. 20a, "External cephalic version and reducing the incidence of breech presentation," December 2006.

[8] F. P. Meehan, N. M. Rafla, and I. I. Bolaji, "Delivery following previous caesarean section," in Progress in Obstetrics and Gynaecology, J. Studd, Ed., vol. 10, chapter 12, pp. 213-228, Churchill Livingstone, London, UK, 1993.

[9] D. P. Cruikshank, "Breech presentation," Clinical Obstetrics and Gynecology, vol. 29, no. 2, pp. 255-263, 1986.

[10] M. E. Hannah, W. J. Hannah, S. A. Hewson, et al., "Planned caesarean section versus planned vaginal birth for breech presentation at term: a randomised multicentre trial," Lancet, vol. 356, no. 9239, pp. 1375-1383, 2000.

[11] I. Hildingsson, I. Rådestad, C. Rubertsson, and U. Waldenström, "Few women wish to be delivered by caesarean section," British Journal of Obstetrics and Gynaecology, vol. 109, no. 6, pp. 618-623, 2002.

[12] J. A. Gamble and D. K. Creedy, "Women's request for a cesarean section: a critique of the literature," Birth, vol. 27, no. 4, pp. 256-263, 2000.

[13] G. J. Hofmeyr and M. E. Hannah, "Planned caesarean section for term breech delivery (Cochrane review)," in Cochrane Database of Systematic Reviews, no. 3, The Cochrane Library, Oxford, UK, 2003.

[14] E. K. Hutton, M. E. Hannah, and J. Barrett, "Use of external cephalic version for breech pregnancy and mode of delivery for breech and twin pregnancy: a survey of Canadian practitioners," Journal of Obstetrics and Gynaecology Canada, vol. 24, no. 10, pp. 804-810, 2002.

[15] H. Minkoff and F. A. Chervenak, "Elective primary caesarean delivery," The New England Journal of Medicine, vol. 384, no. 10, pp. 946-950, 2003.

[16] M. H. Hall and S. Bewley, "Maternal mortality and mode of delivery," Lancet, vol. 354, no. 9180, p. 776, 1999.

[17] M. Waterstone, S. Bewley, and C. Wolfe, "Incidence and predictors of severe obstetric morbidity: case-control study," British Medical Journal, vol. 322, no. 7294, pp. 1089-1094, 2001.

[18] G. M. Cooper, G. Lewis, and J. Neilson, "Editorial I: confidential enquiries into maternal deaths, 1997-1999," British Journal of Anaesthesia, vol. 89, no. 3, pp. 369-372, 2002.

[19] E. Saling and W. Mueller-Holve, "External cephalic version under tocolysis," Journal of Perinatal Medicine, vol. 3, no. 2, pp. 115-122, 1975.
[20] J. DeRosa and L. J. Anderle, "External cephalic version of term singleton breech presentations with tocolysis: a retrospective study in a community hospital," Journal of the American Osteopathic Association, vol. 91, no. 4, pp. 351-357, 1991.

[21] G. J. Hofmeyr, "Interventions to help external cephalic version for breech presentation at term," Cochrane Database of Systematic Reviews, no. 1, Article ID CD000184, 2004.

[22] F. Chenia and C. A. Crowther, "Does advice to assume the knee-chest position reduce the incidence of breech presentation at delivery? A randomized clinical trial," Birth, vol. 14, no. 2, pp. 75-78, 1987.

[23] P. Bung, R. Huch, and A. Huch, "Is Indian version a successful method of lowering the frequency of breech presentations?" Geburtshilfe und Frauenheilkunde, vol. 47, no. 3, pp. 202-205, 1987.

[24] R. L. Johnson and J. P. Elliott, "Fetal acoustic stimulation, an adjunct to external cephalic version: a blinded, randomized crossover study," American Journal of Obstetrics and Gynecology, vol. 173, no. 5, pp. 1369-1372, 1995.

[25] J.-L. Benifla, F. Goffinet, V. Bascou, E. Darai, A. Proust, and P. Madelenat, "Transabdominal amnio-infusion facilitates external version manouver after initial failure," Journal de Gynecologie Obstetrique et Biologie de la Reproduction, vol. 24, no. 3, pp. 319-322, 1995.

[26] Z. West, Acupuncture in Pregnancy and Childbirth, Churchill Livingstone, Edinburgh, UK, 2001.

[27] F. Cardini, V. Basevi, A. Valentini, and A. Martellato, "Moxibustion and breech presentation: preliminary results," American Journal of Chinese Medicine, vol. 19, no. 2, pp. 105114, 1991.

[28] K. M. Mancuso, M. K. Yancey, J. A. Murphy, and G. R. Markenson, "Epidural analgesia for cephalic version: a randomized trial," Obstetrics and Gynecology, vol. 95, no. 5, pp. 648-651, 2000.

[29] S. J. Schorr, S. E. Speights, E. L. Ross, et al., "A randomized trial of epidural anesthesia to improve external cephalic version success," American Journal of Obstetrics and Gynecology, vol. 177, no. 5, pp. 1133-1137, 1997.

[30] C. F. Weiniger, Y. Ginosar, U. Elchalal, E. Sharon, M. Nokrian, and Y. Ezra, "External cephalic version for breech presentation with or without spinal analgesia in nulliparous women at term: a randomized controlled trial," Obstetrics and Gynecology, vol. 110, no. 6, pp. 1343-1350, 2007.

[31] L. Dugoff, C. A. Stamm, O. W. Jones III, S. I. Mohling, and J. L. Hawkins, "The effect of spinal anesthesia on the success rate of external cephalic version: a randomized trial," Obstetrics and Gynecology, vol. 93, no. 3, pp. 345-349, 1999.

[32] M. F. Delisle, A. Kamani, J. Douglas, and M. Bebbington, "Antepartum external cephalic version under spinal anesthesia: a randomized controlled trial," American Journal of Obstetrics and Gynecology, vol. 185, supplement 1, no. 6, p. S115, 2001.

[33] A. Hollard, C. Lyons, P. Rumney, M. Hunter, E. Reed, and M. Nageotte, "The effect of intrathecal anaesthesia on the success of external cephalic version (ECV)," American Journal of Obstetrics and Gynecology, vol. 189, no. 6, p. S140, 2003.

[34] J. T. Sullivan, W. A. Grobman, J. R. Bauchat, et al., "A randomized controlled trial of the effect of combined spinalepidural analgesia on the success of external cephalic version for breech presentation," International Journal of Obstetric Anesthesia, vol. 18, no. 4, pp. 328-334, 2009.

[35] T. M. Cook, D. Counsell, J. A. W. Wildsmith, and on behalf of The Royal College of Anaesthetists Third National Audit Project, "Major complications of central neuraxial block: 
report on the Third National Audit Project of the Royal College of Anaesthetists," British Journal of Anaesthesia, vol. 102, no. 2, pp. 179-190, 2009.

[36] "Early External Cephalic Version 2 (ECV2) Trial," http://www .utoronto.ca/miru/trials.html.

[37] G. J. Hofmeyr, "Effect of external cephalic version in late pregnancy on breech presentation and caesarean section rate: a controlled trial," British Journal of Obstetrics and Gynaecology, vol. 90, no. 5, pp. 392-399, 1983.

[38] S. J. Carlan, J. M. Dent, T. Huckaby, E. C. Whittington, and D. Shaefer, "The effect of epidural anesthesia on safety and success of external cephalic version at term," Anesthesia and Analgesia, vol. 79, no. 3, pp. 525-528, 1994.

[39] R. Neiger, M. Hennessy, and M. Patel, "Reattempting failed external cephalic version under epidural anaesthesia," American Journal of Obstetrics and Gynaecology, vol. 178, no. 1, p. S71, 1998.

[40] R. Neiger, M. D. Hennessy, and M. Patel, "Reattempting failed external cephalic version under epidural anesthesia," American Journal of Obstetrics and Gynecology, vol. 179, no. 5, pp. 11361139, 1998.

[41] A. J. MacArthur, S. Gagnon, L. M. Tureanu, and K. N. Downey, "Anesthesia facilitation of external cephalic version: a metaanalysis," American Journal of Obstetrics and Gynecology, vol. 191, no. 4, pp. 1219-1224, 2004.

[42] G. Cherayil, B. Feinberg, J. Robinson, and L. C. Tsen, "Central neuraxial blockade promotes external cephalic version success after a failed attempt," Anesthesia and Analgesia, vol. 94, no. 6, pp. 1589-1592, 2002.

[43] D. J. Birnbach, J. Matut, D. J. Stein, et al., "The effect of intrathecal analgesia on the success of external cephalic version," Anesthesia and Analgesia, vol. 93, no. 2, pp. 410-413, 2001.

[44] S. D. Pratt, "Anesthesia for breech presentation and multiple gestation," Clinical Obstetrics and Gynecology, vol. 46, no. 3, pp. 711-729, 2003.

[45] S. D. Pratt, "External Cephalic Version under epidural anaesthesia: PRO," Society for Obstetric Anaesthesia and Perinatology (SOAP) Newsletter Highlights, 2001, http://www.soap.org/newsletters/01-winter-spring.pdf.

[46] Health Resource Groups (HRG), The NHS Information Centre for Health and Social care, http://www.ic.nhs.uk/casemix.

[47] Health Resource Group 4 (HRG 4), The NHS Information Centre for Health and Social care, http://www.ic.nhs.uk/ casemix.

[48] "Confirmation of Payment by Results (PbR) arrangements for 2009-10," Department of Health, February 2009, http://www.dh.gov.uk/publications.

[49] J. G. Mauldin, P. D. Mauldin, T. I. Feng, E. K. Adams, and V. L. Durkalski, "Determining the clinical efficacy and cost savings of successful external cephalic version," American Journal of Obstetrics and Gynecology, vol. 175, no. 6, pp. 1639-1644, 1996.

[50] "Support and assurance using the Commissioning for Quality and Innovation (CQUIN) payment framework for the NHS in England 2009/10," Produced by COI for the Department of Health, http://www.dh.gov.uk/publications.

[51] T. K. Lau, K. W. Lo, and M. Rogers, "Pregnancy outcome after successful external cephalic version for breech presentation at term," American Journal of Obstetrics and Gynecology, vol. 176, no. 1, pp. 218-223, 1997. 


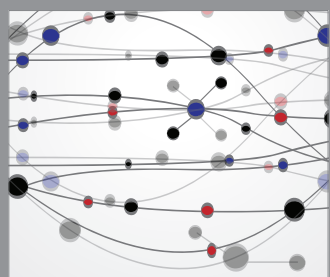

The Scientific World Journal
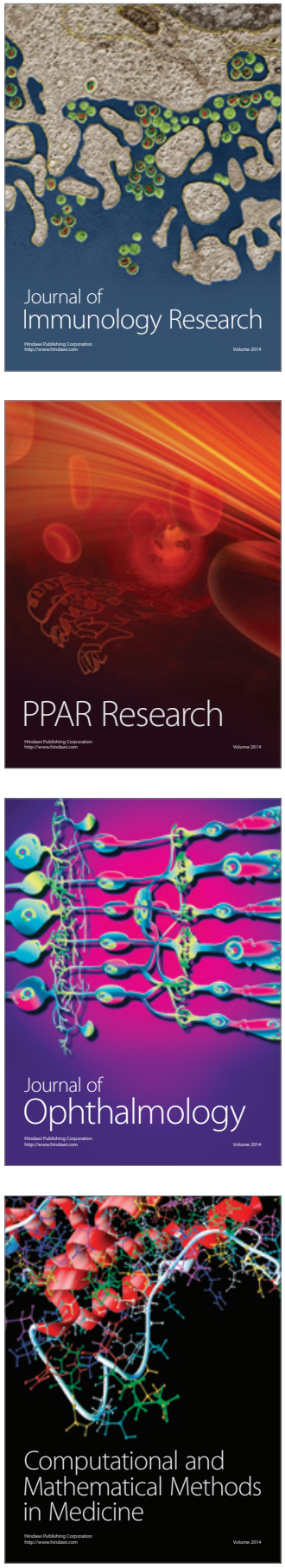

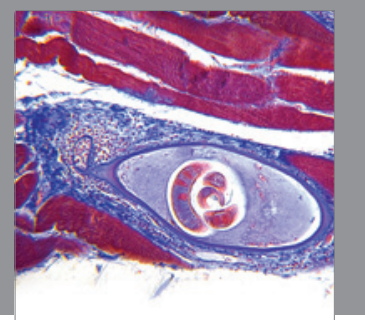

Gastroenterology

Research and Practice
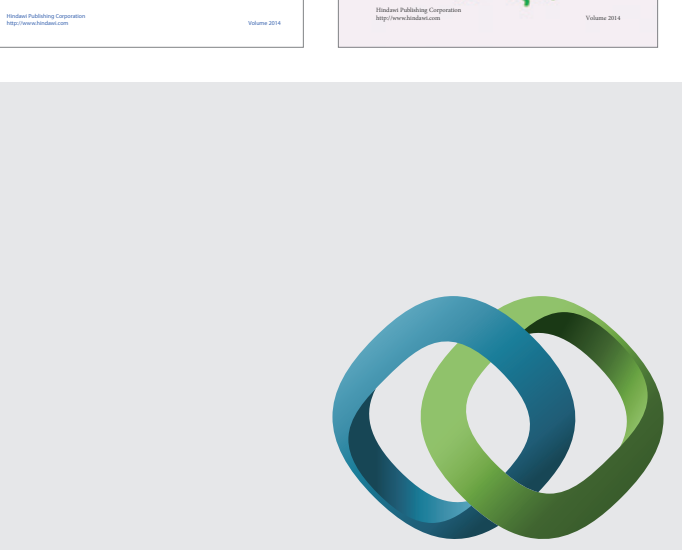

\section{Hindawi}

Submit your manuscripts at

http://www.hindawi.com
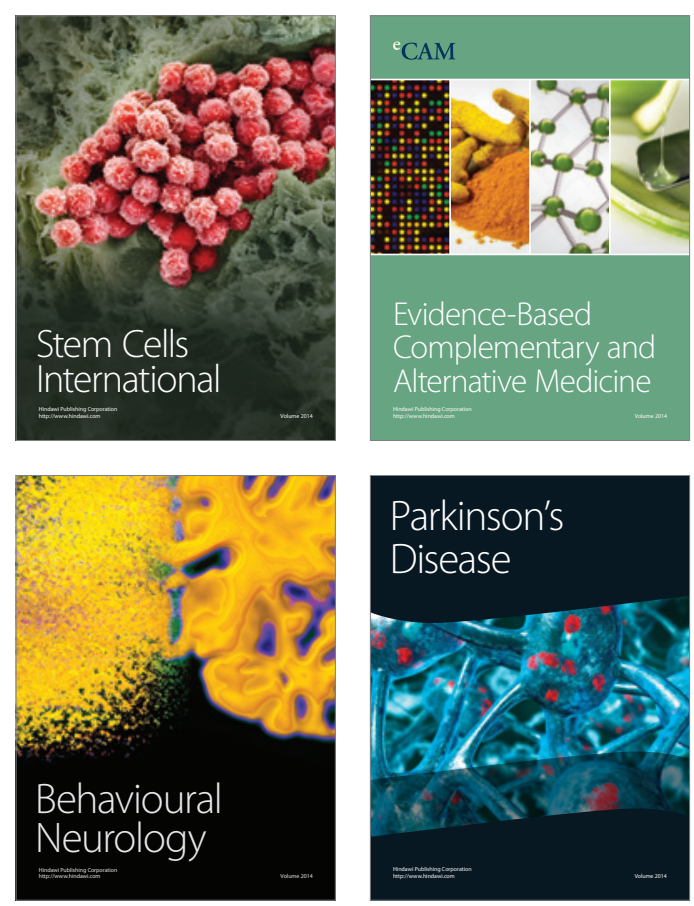

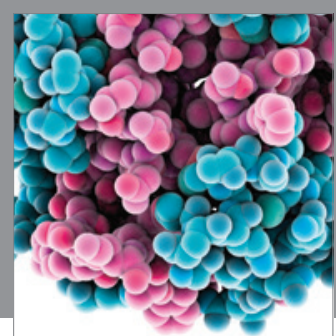

Journal of
Diabetes Research

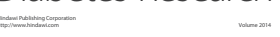

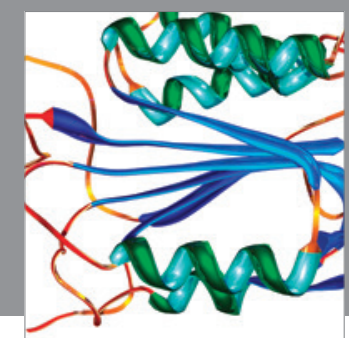

Disease Markers
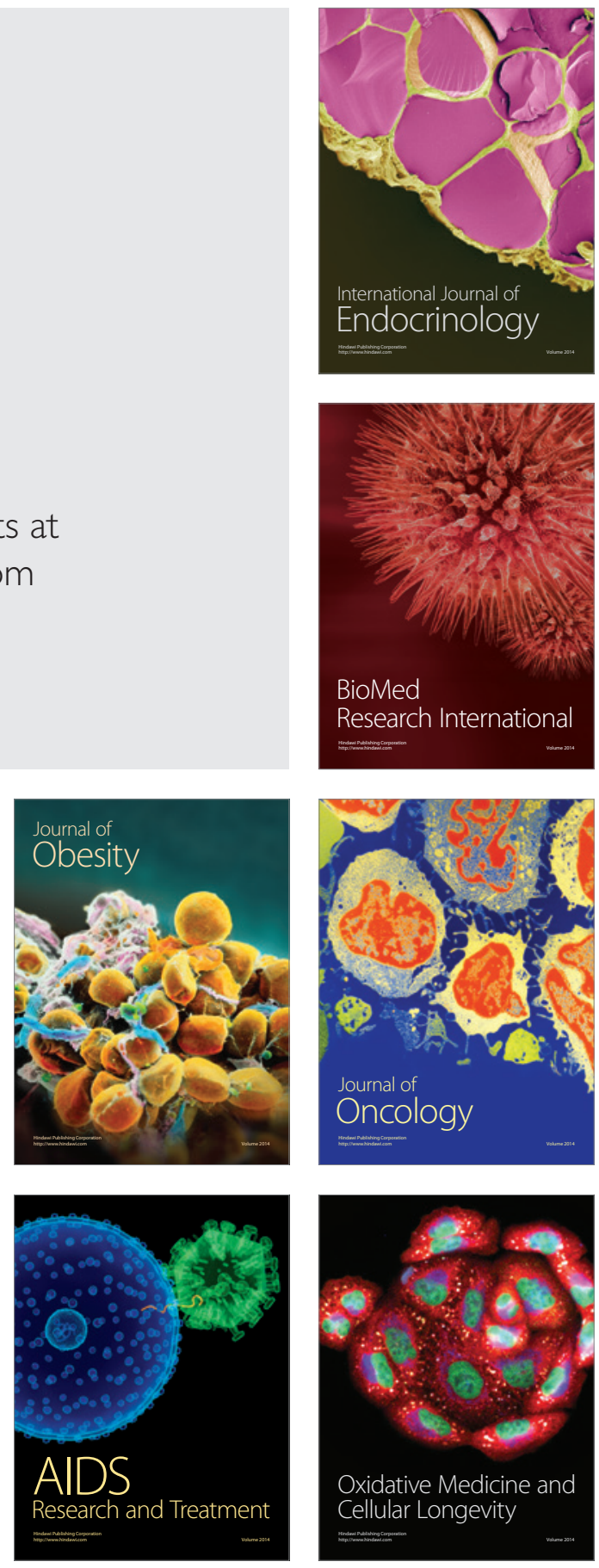